\title{
MECHANISMS CONTROLLING COPULATORY BEHAVIOR IN WOLF SPIDERS \\ (ARANEAE: LYCOSIDAE) ${ }^{1}$
}

\author{
By Jerome S. Rovner \\ Department of Zoology \\ Ohio University \\ Athens, Ohio 45701
}

Male spiders use their palps for picking up, storing, and, finally, transferring seminal fluid to the female's copulatory apparatus. In previous papers (Rovner, in press) I described inter-generic differences in palpal insertion patterns and examined temporal variation in the duration of insertion during mating in the lycosid spiders Lycosa rabida and Schizocosa saltatrix. Using the former species and taking a different perspective in the present study, I sought to determine some of the mechanisms involved in regulating the sequence of events accompanying each palpal insertion, as well as the role of the palps in the orientation of the male throughout mating. Experimental modification of one or the other partner was followed by the male's performance of behaviors which did not occur during normal copulations: courtship, disorientation, tying down the female, and "pseudoinsertions". Such data led to hypotheses concerned with the control of various elements of copulatory behavior.

During mating, lycosid spiders maintain a position (Position II of Gerhardt, 1924) in which the male's sternum is above the female's carapace and the partners face in opposite directions (Fig. I). Each insertion involves the male's leaning down on one side of the female and scraping one palp (the one closest to that side of the female) against her epigynum. The male's right palp serves the female's right copulatory pore; his left palp, her left pore.

One or more scrapes of the palp result in engagement of the embolus in the copulatory pore. The latter is accompanied by hematodochal expansion, which forces the embolus into the duct leading to the seminal receptacle. Ejaculation of seminal fluid through the embolus is presumed to occur at maximum expansion of the hematodocha (Gering, I953). Subsequent collapse of the hematodocha is followed by disengagement of the embolus and lifting of the palp away from the epigynum. (For details of palpal function during copulation, see Gering, 1953. The hydrostatic system involved in hematodochal expansion, as well as in locomotion, has been studied recently by Wilson, I970.)

${ }^{1}$ This study was supported in part by Ohio University Research Grant 244. Manuscript received by the editor, September 27, 1971. 


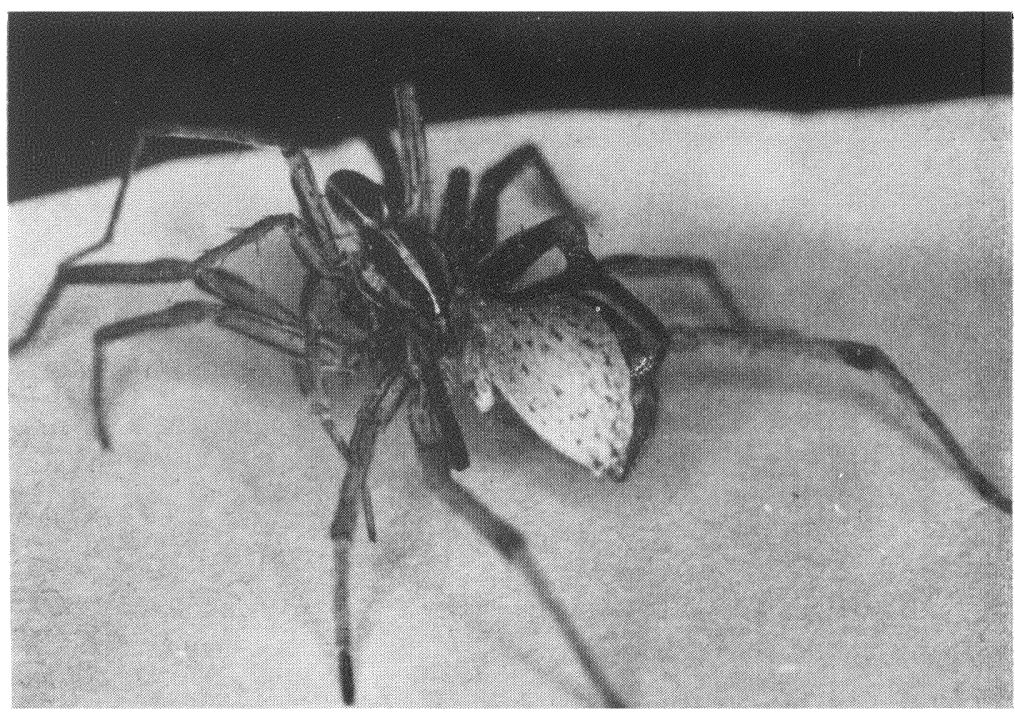

Fig. 1. Male and female Lycosa rabida in copula. The male is above, facing the camera, and has just initiated a pseudo-insertion with his left palp.

After about half of the palpal insertions, male $L$. rabida moisten the palp just used by drawing it between the chelicerae. In such cases, they then usually moisten the opposite palp. Although a bout of palpal moistening often involves a rapid alternation of the palps, it always is initiated in the palp which has just been used in an attempted or completed insertion (Rovner, in press). In about half of the insertion sequences the male, rather than moisten the palps, either remains inactive for several seconds or immediately crosses over to the female's opposite side.

Whether or not palpal moistening occurs, male L. rabida then shift over to the female's opposite side; i.e., palpal alternation is the insertion pattern in this species (Montgomery, 1903). While moving from one side to the other, the male usually taps his palps against the anterior dorsal surface of the female's abdomen. At this time the female performs the only behavior shown by her during most of the copulation - abdominal swiveling. Her abdomen rotates about its longitudinal axis during each crossing by the male, thereby bringing the epigynum within reach of the male's palp.

The above palpal insertion sequence, which is repeated an average of about sixty times by each palp during copulation in L. rabida, is 


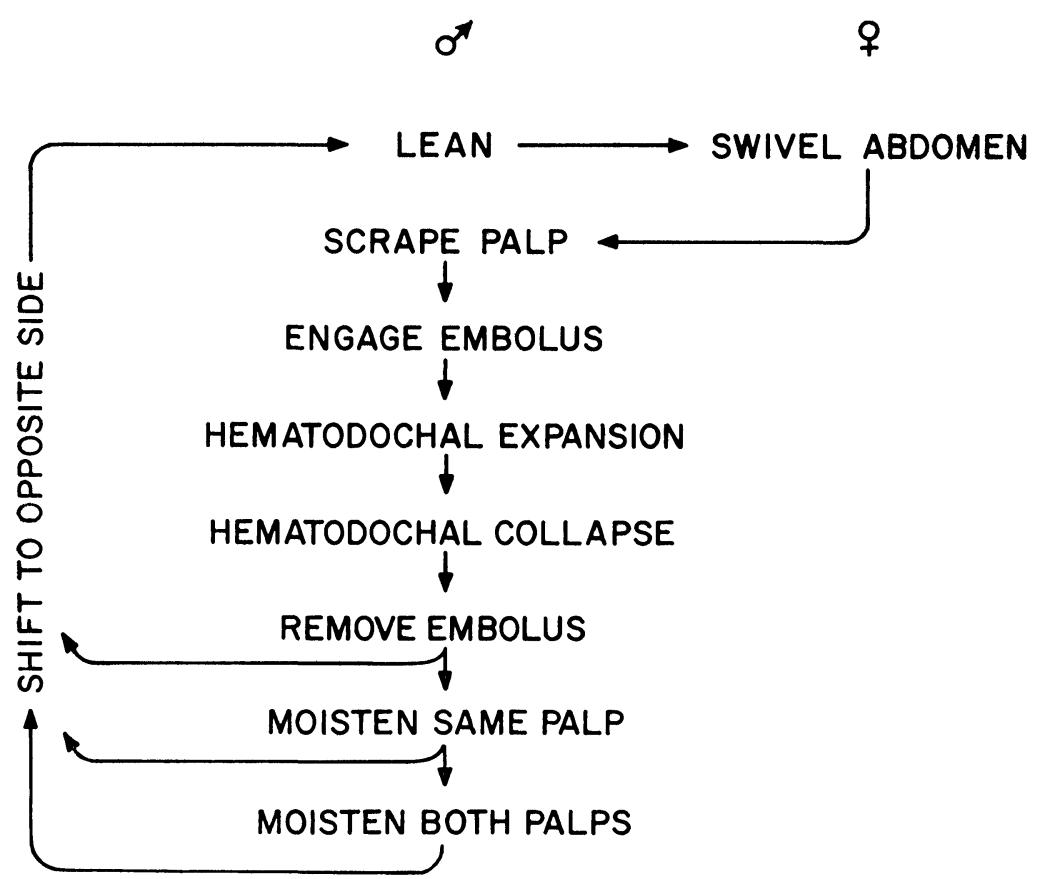

Fig. 2. Sequence of events associated with each palpal insertion during copulation in Lycosa rabida.

summarized in Fig. 2. Some of the mechanisms associated with these events were suggested by the findings of the present study. Specific questions that I was asking were these: (I) Given that the palps serve for transfer of sperm, how essential is sensory information from the palps to the maintenance of the male's copulatory state? (2) Given that the palps may be aiding in a sensory capacity to locate a target, the female's epigynal openings, is information from the palps important for the male's orientation on the female? (3) Does the pattern of right-left alternation persist after unilateral modification of the male, or will the spider learn to favor the functioning palp? (4) What stimulus determines which palp is moistened first after each insertion? (5) What action by the male elicits abdominal swiveling in the female?

\section{Methods}

Over one hundred individuals of $L$. rabida were collected as immature instars during June, I968, in a field near Athens, Ohio, 
U. S. A. Each was housed separately in a glass jar prior to pairing in the observation arena. Mealworms (Tenebrio sp.) served as food; and cotton-stoppered, water-filled vials provided moisture.

Observations on copulatory behavior were made at temperatures of $24-26^{\circ} \mathrm{C}$. A manually activated Esterline Angus event recorder, at a chart speed of $15.3 \mathrm{~cm} / \mathrm{min}$, was used to record some of the data. Protocol was whispered into the microphone of a tape recorder. Recording instruments were placed on a separate table to reduce possible effects of machine noise.

This study involved fifty pairings of virgin, adult spiders. (Although housed individually until that time that the mating partners were placed into the arena, the spiders will be referred to in terms of this eventual pairing.) Ten pairs of spiders were not modified experimentally; and their behavior represented that of normal individuals. The remaining forty pairs were divided into the following eight groups, each consisting of five pairs: (I) Males losing both palps prior to the final molt; (2) Males losing both palps after the final molt; (3) Males with both palps fixed dorsally; (4) Males losing one palp prior to the final molt; (5) Males losing one palp after the final molt; (6) Males with one palp fixed dorsally; ( 7 ) Females with both copulatory pores sealed; (8) Females with one copulatory pore sealed.

Palp removal was accomplished by autotomy. During carbon dioxide-induced anesthesia, the male's palp was attached to the substratum. After the male's recovery I prodded him with an artist brush and forced him to pull away from the point of attachment, which resulted in palpal autotomy at the trochantero-femoral joint. This was repeated for males undergoing loss of both palps. When autotomy involved penultimate males, a "stump" or a complete but vestigial palp was present after the final molt. In the latter case the tarsus lacked a genital bulb.

Fixation of a palp above the cephalothorax involved positioning the palp into a drop of melted paraffin placed on the adjacent region of the carapace of the anesthetized spider. Paraffin was also used to cover the copulatory pores of anesthetized females.

All operations were performed under a dissecting microscope. In each experimental group of five pairs which involved unilateral modification, three individuals were treated on one side (e.g., right palp) and two on the other side (e.g., left palp).

\section{Results}

A variable period of time after mounting the female, many of the males of the experimental pairs performed behaviors which were not 


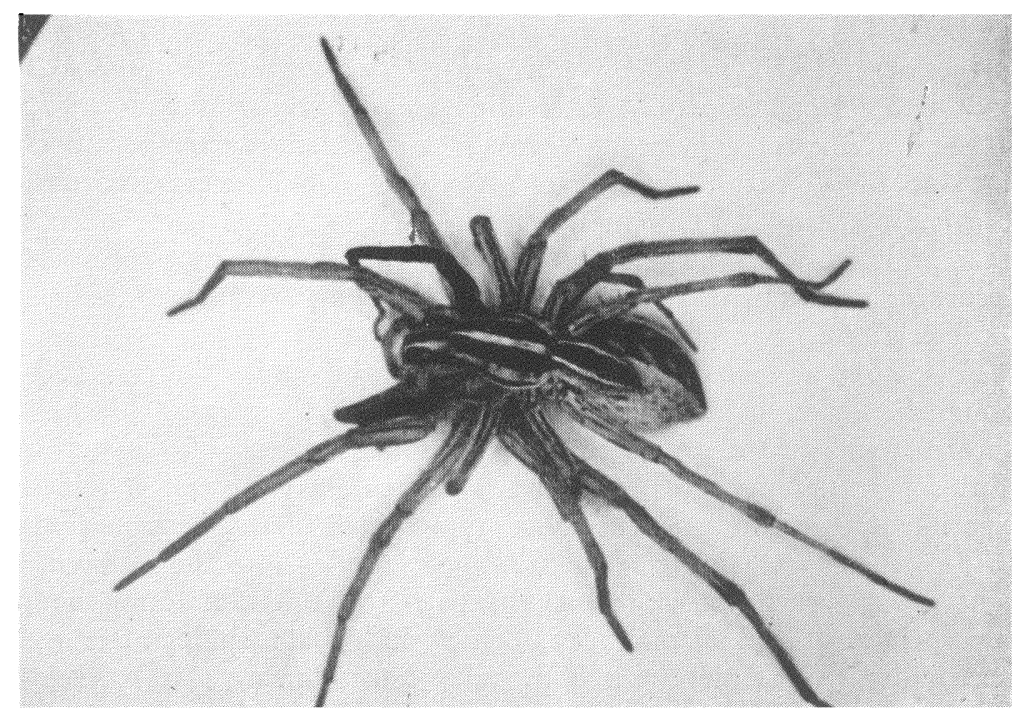

Fig. 3. Male Lycosa rabida disoriented $180^{\circ}$ from the normal position while above the female in cotula.

observed during copulation in the normal pairs in this or previous studies of lycosid mating behavior.

Males unable to use one or both palps (due to modification of the males) performed courtship display at various times while mounted on the female. Those males possessing one usable palp often followed each successful insertion with a brief period of courtship that was initiated after the shift to the non-functional side and the subsequent adoption of a medial position. Thus the male alternated copulation with courtship. In some cases, courtship was initiated soon ofter mount; e.g., one male began to display after having successfully inserted the functional palp only three times.

Males possessing one usable palp always shifted either to a medial position or completely over to the non-functional side after each successful insertion. However, when visiting the non-functional side, these males typically did not lean ventrad as steeply as did normal males. After resting momentarily, the experimental males either shifted back immediately to the functional side or initiated a bout of courtship display. The average duration of insertion of the functional palp in these males ranged from 7.1 sec in one male to 15.8 in another. 


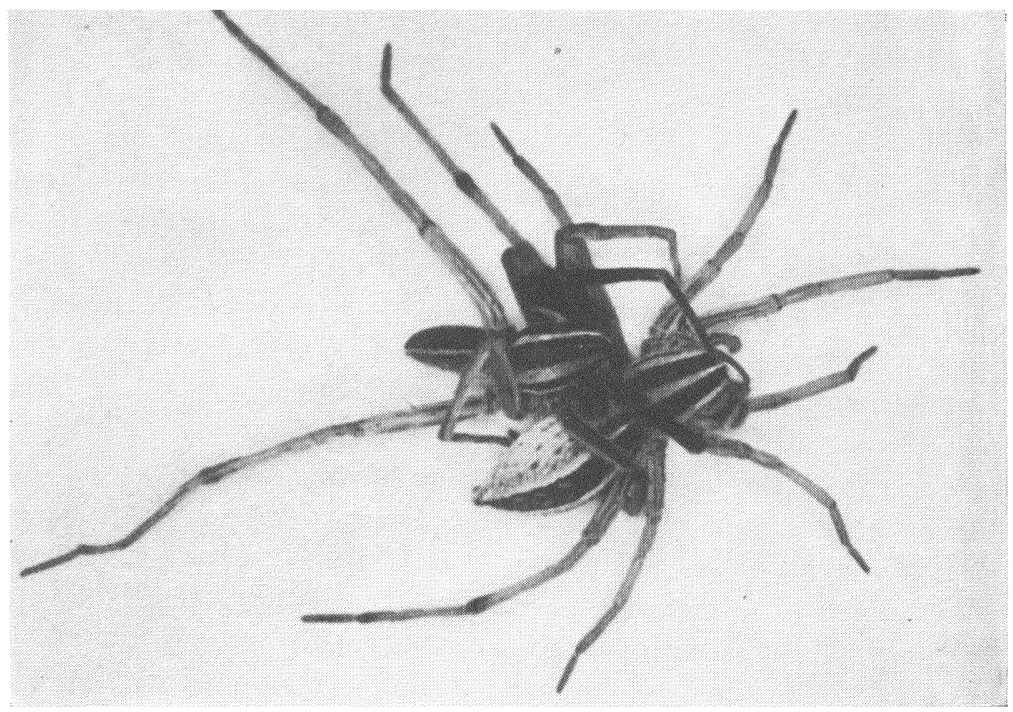

Fig. 4. Palpless male Lycosa rabida disoriented from the normal position and using his black legs I to perform elements of courtship display while above the female in copula.

Disorientation was shown by most of the males which lacked the use of both palps (due to modification of the males). In this behavior the male pivoted on the female's carapace in a clockwise or counter-clockwise direction and temporarily adopted a position other than the normal one. The most typical and most prolonged abnormal position was that in which the male was $180^{\circ}$ out of proper alignment, i.e., facing in the same direction as the female (Fig. 3). The next most common abnormal position was one of $90^{\circ}$ mis-alignment, i.e., the male's longitudinal axis perpendicular to that of the female. As "copulation" progressed, the male adopted positions even further removed from the normal one by locating himself above the basal segments of the female's legs on one side (Fig. 4). While in the various abnormal positions, the male spent much of his time in courtship display.

Whether in the normal position or disoriented $180^{\circ}$, males lacking the use of both palps (due to modification of the males) showed bouts of rapid, oscillatory movements, in which the male either shifted from side to side or slid forward and back while above the female's carapace. Such bouts of activity were variable in duration, on the average lasting $6.8 \mathrm{sec}(\mathrm{N}=\mathrm{I} 4 \mathrm{O})$. During these excited 
movements, the male scraped his chelicerae against the female's carapace (or, rarely, abdomen) and alternately spread and closed the chelicerae as they slid over the female's surface. Some of these bouts terminated with the male's use of his chelicerae to grasp the rim of the female's carapace or a basal segment of one of her appendages and to lift that end of her body dorsad. Synchronous erection of his leg spines accompanied each tug by the male. The female did not respond to the male's tugs, even though: (I) males disoriented $180^{\circ}$ tugged at structures near the female's face; and (2) puncture of a joint membrane and loss of a drop of hemolymph occurred in a few females due to the male's vigorous cheliceral grasping. After one or more tugs, the male became inactive but maintained his hold on the female with his chelicerae. The pattern of behavior in males lacking the use of both palps was that of an alternation of inactive periods (with the male located medially or leaning slightly to one side of the female) with periods involving one or more of the abovedescribed behaviors. Abdominal vibrations continued during the male's inactive periods.

Half of the males with both palps unavailable and one-fifth of the males with one palp unavailable occasionally performed "tying down". In this behavior the male pivoted on the female's carapace in a clockwise or counter-clockwise direction while laying down a barely visible silk line over the legs and abdomen of the female. The silk on the legs usually contacted the patellar and tibial segments; less frequently, the femora. At a few points in the crude circle, the silk was attached to the substratum. During tying down the male typically moved through a complete $360^{\circ}$ and resumed the normal position. Less often the male momentarily stopped at $180^{\circ}$ and then returned to the normal position by either continuing to $360^{\circ}$ or reversing direction and covering the same ground again. Even though the male stopped briefly at $180^{\circ}$ (or, rarely, $90^{\circ}$ or $270^{\circ}$ ), he did not initiate any other behavior at these points, but soon resumed tying down in a return to the normal position. Thus, tying down was distinct from the behavior described above as disorientation, in that the latter: (I) did not involve release of silk; (2) involved pivoting through arcs of $180^{\circ}$ or less; and (3) usually was accompanied by other behaviors while the male was in an abnormal position. 'Tying down was shown in pairs in which the female was inactive throughout the copulation (except for abdominal swiveling); i.e., tying down typically was neither preceded nor followed by activity in the female. When resuming locomotion at the end of the 
mating, females which had undergone one to several bouts of tying down were only slightly hampered by the scant threads on their legs and readily freed themselves.

Most of the normal males copulating with females that had one or both copulatory pores sealed performed an atypical behavior which I have termed a "pseudo-insertion". This occurred when one of the palpal scrapes (insertion attempts) on an unavailable side resulted in complete expansion of the hematodocha, even though the palp was no longer in contact with the female's body. Synchronously with the hematodochal expansion, the palp was lifted dorsad, sometimes to a relatively high position (with the palpal femur about $45^{\circ}$ above the horizontal plane). Leg spine erection accompanied hematodochal expansion, as in normal insertions. The palp was lowered ventrad (and the leg spines dropped) during the subsequent hematodochal collapse. Pseudo-insertion duration averaged $\mathrm{I} 5.5 \mathrm{sec}(\mathrm{N}=20)$. Pseudo-insertions began to occur during a copulation after the male had made a number of visits to an unavailable side of the female. During each visit males made from one to ten (usually from two to five) attempts to insert. A pseudo-insertion usually occurred after five or fewer attempts; in some cases later in copulation, the first attempt during a visit to one side resulted in a pseudo-insertion. In many cases if the hematodocha began expansion after partial engagement of the embolus in the paraffin seal, expansion would continue to completion after the palp slipped away from the epigynum. In other instances the palpal tarsus would swing down to the base of the female's leg IV and, meeting resistance there, give rise to a pseudoinsertion. The number of pseudo-insertions performed during such pairings ranged from one to seventeen.

Two males lacking one palp and having difficulty inserting the available palp showed pseudo-insertions, as well as courtship and tying down. Males having one or both palps fixed dorsad did not perform pseudo-insertions with their treated palps.

A behavior probably related to the mechanism underlying pseudoinsertions was also seen in the males which were paired with females having one or both copulatory pores sealed. It occurred while the male was resting on one side of the female after a series of insertion attempts. (Many of these attempts involved the male's leaning steeply and scraping his palp much further posterior than the female's epigynum, sometimes thereby contacting her spinnerets.) During this resting period, while the male held his palp near his face, slow and weak pulsations were evident in the genital bulb. During this "throbbing" the hematodocha was not visible. Partial, synchronous leg spine erections accompanied the genital bulb pulsations. 
Table I.

Behaviors shown during copulation by males of treated and untreated pairs of Lycosa rabida. (The first figure represents the number of males showing that behavior; the next figure, the number of males tested.)

\begin{tabular}{|c|c|c|c|c|}
\hline & Courtship & Disorientation & $\begin{array}{l}\text { Tying } \\
\text { down }\end{array}$ & $\begin{array}{l}\text { Pseudo- } \\
\text { insertion }\end{array}$ \\
\hline $\begin{array}{l}\text { Both of palps } \\
\text { lacking }\end{array}$ & $7 / 10$ & $6 / 10$ & $3 / 10$ & - \\
\hline $\begin{array}{l}\text { Both ô palps } \\
\text { fixed dorsad } \\
\text { One } \hat{\alpha} \text { palp }\end{array}$ & $5 / 5$ & $4 / 5$ & $4 / 5$ & $0 / 5$ \\
\hline $\begin{array}{l}\text { lacking } \\
\text { One ô palp }\end{array}$ & $4 / 10$ & $1 / 10$ & $2 / 10$ & $2 / 10$ \\
\hline $\begin{array}{l}\text { fixed dorsad } \\
\text { Both } q\end{array}$ & $4 / 5$ & $1 / 5$ & $1 / 5$ & $0 / 5$ \\
\hline $\begin{array}{l}\text { pores sealed } \\
\text { One }+\end{array}$ & $1 / 5$ & $0 / 5$ & $0 / 5$ & $4 / 5$ \\
\hline $\begin{array}{l}\text { pore sealed } \\
\hat{\delta} \text { and } q\end{array}$ & $2 / 5$ & $0 / 5$ & $0 / 5$ & $4 / 5$ \\
\hline untreated & $0 / 10$ & $0 / 10$ & $0 / 10$ & $0 / 10$ \\
\hline
\end{tabular}

Many of the above results are summarized in Table I. Data for males treated prior to the final molt are grouped with those for males treated similarly after the final molt. There did not seem to be a difference in performance between the pre- and the post-molt-treated males. Further reduction of the data is provided in Table II, in which experimental pairings are reduced to three classes of treatment.

Details of palpal moistening behavior were studied in the various experimental pairs. Males entirely lacking one palp moistened the available palp only after using it in an insertion or an insertion attempt. They did not perform moistening of the available palp after visiting the palpless side. Some males of this experimental category possessed a vestigial palp (complete but smaller and lacking a genital bulb). Insertion attempts with the latter were accompanied by synchronous leg spine erections, but were not followed by palpal moistening. On the other hand, after insertions or insertion attempts of the functional palp, both palps were involved in bouts of palpal moistening. In pairings of normal males with females having sealed copulatory pores, many of the groups of insertion attempts culminated in a bout of palpal moistening, which always began with the palp used in the attempts.

Males having both palps fixed dorsad and males lacking both palps performed behavior associated with moistening of the unavailable palps. After adopting a medial position above the female's carapace and tilting his body caudad, such a male alternately spread and closed his chelicerae for a period of time in a manner similar to that 
Table II.

Percentages of male Lycosa rabida performing various behaviors during copulation. (This summary was obtained by appropriate re-groupings of the data presented in Table I.)

$\begin{array}{lcccc}\text { Courtship } & \begin{array}{c}\% \\ \text { Disorientation }\end{array} & \begin{array}{c}\% \text { Tying } \\ \text { down }\end{array} & \begin{array}{c}\% \text { Pseudo- } \\ \text { insertion }\end{array} \\ \begin{array}{l}\text { Both ô palps } \\ \text { unavailable }\end{array} & 80.0 & 66.7 & 46.7 & - \\ \begin{array}{l}\text { One ô palp } \\ \text { unavailable }\end{array} & 53.3 & 13.3 & 20.0 & 13.3 \\ \begin{array}{l}\text { One or both }+ \\ \text { pores unavailable }\end{array} & 30.0 & 0.0 & 0.0 & 80.0 \\ \begin{array}{c}\text { and } \$ \\ \text { untreated }\end{array} & 0.0 & 0.0 & 0.0 & 0.0\end{array}$

seen during normal moistening. Likewise, those males in which only one palp was fixed dorsad alternated moistening of the available palp with periods in which the cheliceral movement continued without the available palp being drawn between the chelicerae.

Males unable to insert one palp due to unilateral modification of themselves or their partners usually shifted over to that unavailable side after a successful insertion. After a bout of attempted insertions and palpal moistening or a period of inactivity on the unavailable side, the male shifted back to the functional side. In other words, throughout most of the copulation such males maintained a pattern of right-left alternation and did not remain on one side or the other for an extensive period of time. Towards the end of the mating, some of the males paired with females having one pore sealed did tend to perform an increased number of insertion attempts on the sealed side. Another irregularity in the right-left pattern which occurred occasionally in males of various experimental pairings was the attempted use of the "wrong" palp while on one side of the female. For example, while on the female's right side, the male would press his left palp against the base of the female's right leg IV and achieve a partial (or, rarely, complete) hematodochal expansion.

Females paired with males lacking both palps or males having both palps fixed dorsad showed appropriate abdominal swiveling when the male shifted from one side to the other. Abdominal swiveling was also elicited experimentally in females that had remained in the so-called cataleptic state after the male's dismount, as well as in a few females which had already resumed an active state, e.g., a defensive posture. In the latter instances, the females returned to the passive copulatory condition when I pressed down on their posterior carapace with a probe. Abdominal swiveling was subsequently elicited in the below-described manner. It was also possible to elicit abdom- 


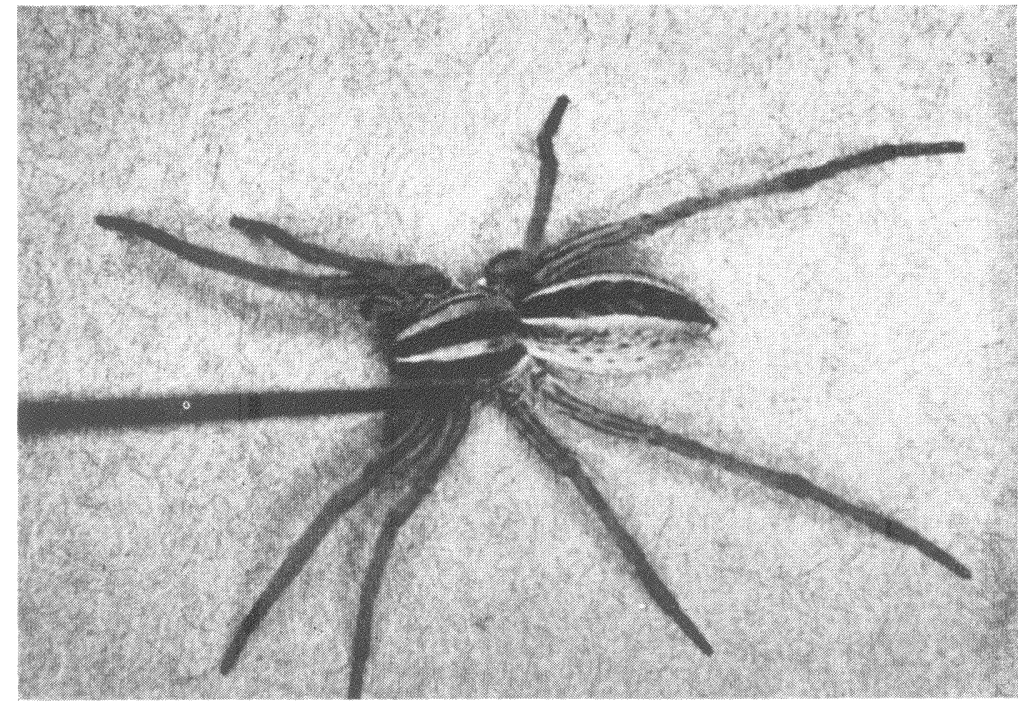

Fig. 5. Female Lycosa rabida being tested after the male's dismount. She has responded to tactile stimulation of the left posterior region of her carapace by swiveling her abdomen so as to raise the left side dorsad. (Note that the medial dark band on her abdomen is in line with the right dark band on her carapace.)

inal swiveling in a few females that had initiated catalepsis prior to the male's mount in apparent response to the male's courtship display alone. In all of these cases, tactile stimulation of various regions of the female's cephalothorax and abdomen with an artist brush or a probe revealed that maximal abdominal swiveling was elicited by touching the posterior quarter of the carapace. (Tactile stimulation of the more anterior portions of the carapace or of the anterior lateral sides of the abdomen yielded weaker swiveling responses.) Touching the right side of the posterior carapace resulted in a single abdominal movement which brought the right epigynal pore to a more dorsad position; touching the left posterior carapace elicited the corresponding abdominal swiveling (Fig. 5). I could go from side to side with the probe in this manner and elicit appropriate abdominal movements in relatively rapid succession. If both sides of the female's carapace were pressed simultaneously, her abdomen was held medially and swiveled very slightly from side to side in alternation.

Copulations in most experimental categories were similar in duration to those observed in normal pairs (average duration for the lat- 
ter $=\mathrm{I}$ hr $)$. Males having both palps fixed dorsad tended to remain on the female an average of $2 \mathrm{hr}$. $(\mathrm{N}=5)$.

The data presented in Tables I and II reflected in some cases the influence of variables other than those suggested by the type of experimental treatment. A few of the males with one palp unavailable were unable to achieve insertion with the remaining palp. As the hematodocha approached maximal expansion, a drop of hemolymph issued from some point in or near the palpal tarsus. This drop, roughly having a diameter as great or greater than the width of the palpal tarsus, was then sucked up by the male. In such cases the male performed only a few insertions and thereafter behaved as did males lacking the use of both palps. (Although such a malfunction seemed to be related to the presence in such males of only one usable palp, I later observed such a "leaking palp" in a normal malẹ.)

Level of activity in the female was another variable in these experiments. In the majority of pairings, the females remained inactive (except for abdominal swiveling) throughout copulation. However, a few females initiated periods of locomotor activity (including carrying the male to another part of the arena), particularly those females whose partners had both palps unavailable. The frequency or duration of various behaviors in the male may have been influenced by such behavior in the female.

\section{Discussion}

Sensory information from the palps was important for maintenance of the male's copulatory state. While mounted on the female, males unable to use one or both palps (due to modification of the male) performed courtship displays and bouts of tying down. In normal males proprioceptive feedback from insertions probably reduced the likelihood that the male would switch back to an earlier behavior, courtship display, or switch to an out-of-context behavior, tying down. (A behavior similar to tying down sometimes occurred in normal, solitary individuals in response to recently captured large prey such as adult field crickets, Gryllidae.) It is unlikely that tying down served to facilitate the male's post-copulatory escape, in that: ( I) females were only slightly, if at all, hindered by the few threads of silk; and (2) normal males did not employ any such device during mating but did use a cheliceral pinch at the time of dismounting to aid in escape (Rovner, in press).

Among normal males paired with females having one or both copulatory pores sealed, three males showed courtship and none, tying down. Thus, even though unable to insert one or both palps, these males generally did not switch to inappropriate behaviors nor 
did they become disoriented. It is likely that: (I) their ability to achieve numerous, partial hematodochal expansions during insertion attempts provided sufficient feedback for maintenance of the copulatory mode, and (2) the availability of the palps for sensory purposes provided input for orientation purposes.

The early occurrence of courtship after mount by some of the males lacking one palp suggested that there was a relatively independent insertion tendency for each palp. Even though able to successively insert the remaining palp, such males were still motivated to insert the absent palp and, when unable to do so, switched back to pre-copulatory display behavior for a period of time rather than continue to use the functional palp.

A relative independence of insertion tendency for each palp was also suggested by the change in behavior towards the end of copulation in males paired with females having one copulatory pore sealed. Such males continued their insertion attempts on the unavailable side but decreased their visits to the functional side. This indicated that the motivation underlying insertions of the functional palp had decreased to a minimal level as a result of numerous successful insertions.

Peripheral input from the palps seemed important for the male's positioning on the female. Two-thirds of the males in which both palps were unavailable showed disorientation at various times while above the female. Since disorientation usually involved a $180^{\circ}$ misalignment, it seemed likely that input from other parts of the body, probably the sternum and legs, served for maintenance of a medial position (above and in line with the female) and that input from the palps determined the correct anterior-posterior orientation. This is quite different from the control system in a linyphiid spider studied in this regard (Rovner, 1967). Palpless male Linyphia triangularis maintain a normal position throughout "copulation" (both partners hanging inverted, facing in opposite directions, and the male's head pivoting on or near the female's chelicerae). In the latter case, information from tactile hairs on the anterior dorsal point of the male's pars cephalica (and probably the legs also) suffices for orientation.

Most of the males copulating with females whose genital openings were sealed performed pseudo-insertions. This behavior was a response to sub-normal releasing stimuli, in that the entire cycle of events associated with a palpal insertion occurred without successful engagement of the embolus. It seemed that the threshold for release of complete hematodochal expansion gradually lowered during a succession of insertion attempts. At some point, an initiated expansion went to completion without the normally necessary engagement 
of the embolus. One interpretation is that the motivation for palpal insertion built up under the maximal stimulation of repeated, unsuccessful insertion attempts and that the complete behavior finally was released. Theoretical considerations aside, pseudo-insertion behavior may be of interest to workers studying the mechanics of palpal insertion in spiders. In a pseudo-insertion the entire genital bulb, which is only partly visible when pressed tightly against the female's epigynum during a normal insertion, is brought into view during hematodochal expansion and collapse.

In a previous paper on L. rabida (Rovner, in press) I had emphasized that the palp just used in an insertion was the palp employed first in a bout of palpal moistening. The question remained as to what aspect of the insertion sequence served as the stimulus determining the latter. Three observations in the present study provided evidence for an hypothesis: ( I) Males lacking one palp moistened the remaining palp only after insertions or insertion attempts with the latter. (2) Males with vestigial palps (lacking genital bulbs) did not initiate moistening of these palps after using them in attempted insertions. (3) Normal males unable to insert one or both palps (due to closure of the female's copulatory pores) moistened the palp just used in an insertion attempt. Apparently the stimulus normally releasing palpal moistening was associated with the onset of hematodochal expansion, which accompanied the palpal scrape of an insertion attempt. (According to Gering, 1953, hematodochal expansion is initiated as the palp swings downward at the outset of an insertion attempt.) Thus, the proprioceptive stimuli associated with the initial phase of an insertion probably were the ones determining which palp would initiate the subsequent bout of palpal moistening.

The occurrence in palpless males and males with their palps fixed dorsad of cheliceral movements like those seen during palpal moistening indicated that the onset and maintenance of this behavioral pattern did not depend on stimuli resulting from the grasping of the palp by the chelicerae. The "chewing" movements occur in vacuo. A similar phenomenon was reported in palpless male Linyphia triangularis (Rovner, 1967).

Persistence of the pattern of right-left alternation in males unable to insert one of their palps suggested that this pattern was not altered by the experience of repeated failures on the non-functional side. At no point in copulation did males begin to favor the functioning palp by remaining on that side of the female. Males typically shifted, however briefly, to the non-functional side, a behavior which, in normal males, initiated another palpal insertion. 
Various evidence gathered in this study indicated that abdominal swiveling was elicited in the female primarily by the male's leaning against the side of the female's posterior carapace. Palpal tapping, one of the most obvious aspects of the male's behavior during his shift to the opposite side, had been suggested to be the stimulus releasing abdominal swiveling (Hallander, I966). However, the latter seemed to play a minimal role, if any, in triggering the female's response. (Perhaps palpal tapping, if it did indeed have a function, represented an exploratory behavior aiding the male in his orientation on the female.) The observation that simultaneous stimulation of both sides of the female's carapace resulted in a medial abdominal position (with weak side-to-side swiveling) suggested that bilateral input resulted in a bilateral response, in which the motor mechanism for both sides was activated.

\section{Summary}

Studies involving experimentally modified Lycosa rabida suggested some of the mechanisms controlling various aspects of copulatory behavior. Both maintenance of the copulatory state and proper positioning of the male depended on input from the palps. There existed an independent insertion tendency for each palp. Males with modified palps showed courtship, tying down, and disorientation. Pseudo-insertions occurred in normal males paired with females having sealed copulatory pores. Inability to insert one palp did not eliminate the pattern of shifting from side to side on the female. Events associated with partial hematodochal expansion provided adequate stimuli for eliciting moistening of the palp. Cheliceral movements typical of palpal moistening occurred in palpless males. Mechanical stimuli resulting from the male's leaning against one side of the female's carapace released her abdominal swiveling response.

GerhardT, U.

\section{Literature Cited}

1924. Weitere Studien über die Biologie der Spinnen. Arch. Naturgesch. 90: 85-192.

Gering, R. L.

1953. Structure and function of the genitalia in some American agelenid spiders. Smithsonian Inst. Misc. Collect. 121, No. 4.

Hallandek, H.

1967. Courtship display and habitat selection in the wolf spider Pardosa chelata (O. F. Müller). Oikos 18: 145-150.

Montgomery, T. H. Jr.

1903. Studies on the habits of spiders, particularly those of the mating period. Proc. Acad. Nat. Sci. Philad. 55: 59-149. 
Rovner, J. S.

1967. Copulation and sperm induction by normal and palpless male linyphiid spiders. Science 157:835.

In press. Copulation in the lycosid spider Lycosa rabida Walckenaer: a quantitative study. Anim. Behav.

In press. Copulation in the lycosid spider Schizocosa saltatrix (Hentz); an analysis of palpal insertion patterns. Anim. Behav.

Wilson, R. S.

1970. Some comments on the hydrostatic system of spiders (Chelicerata, Araneae). Z. Morph. Tiere 68: 308-322. 

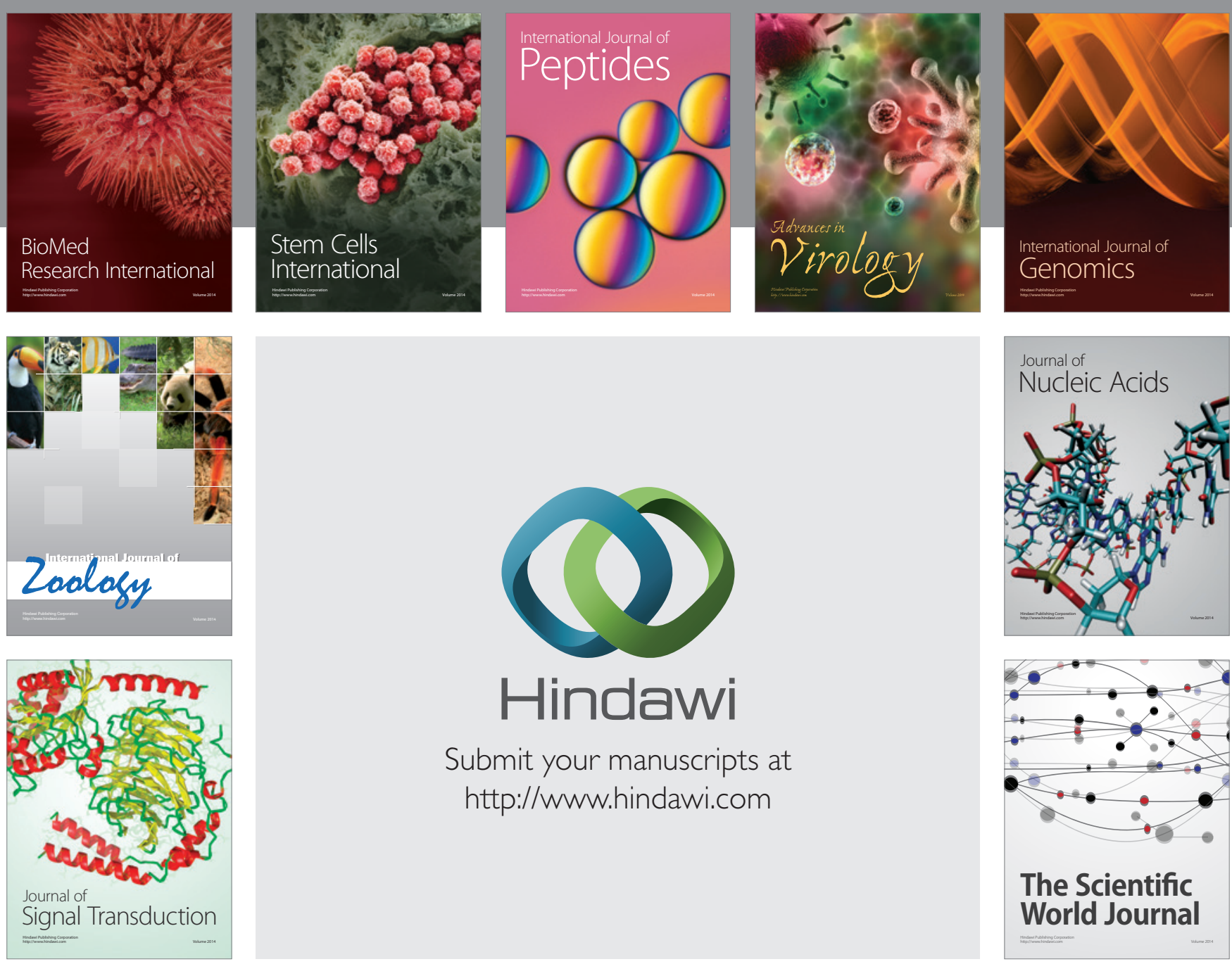

Submit your manuscripts at

http://www.hindawi.com
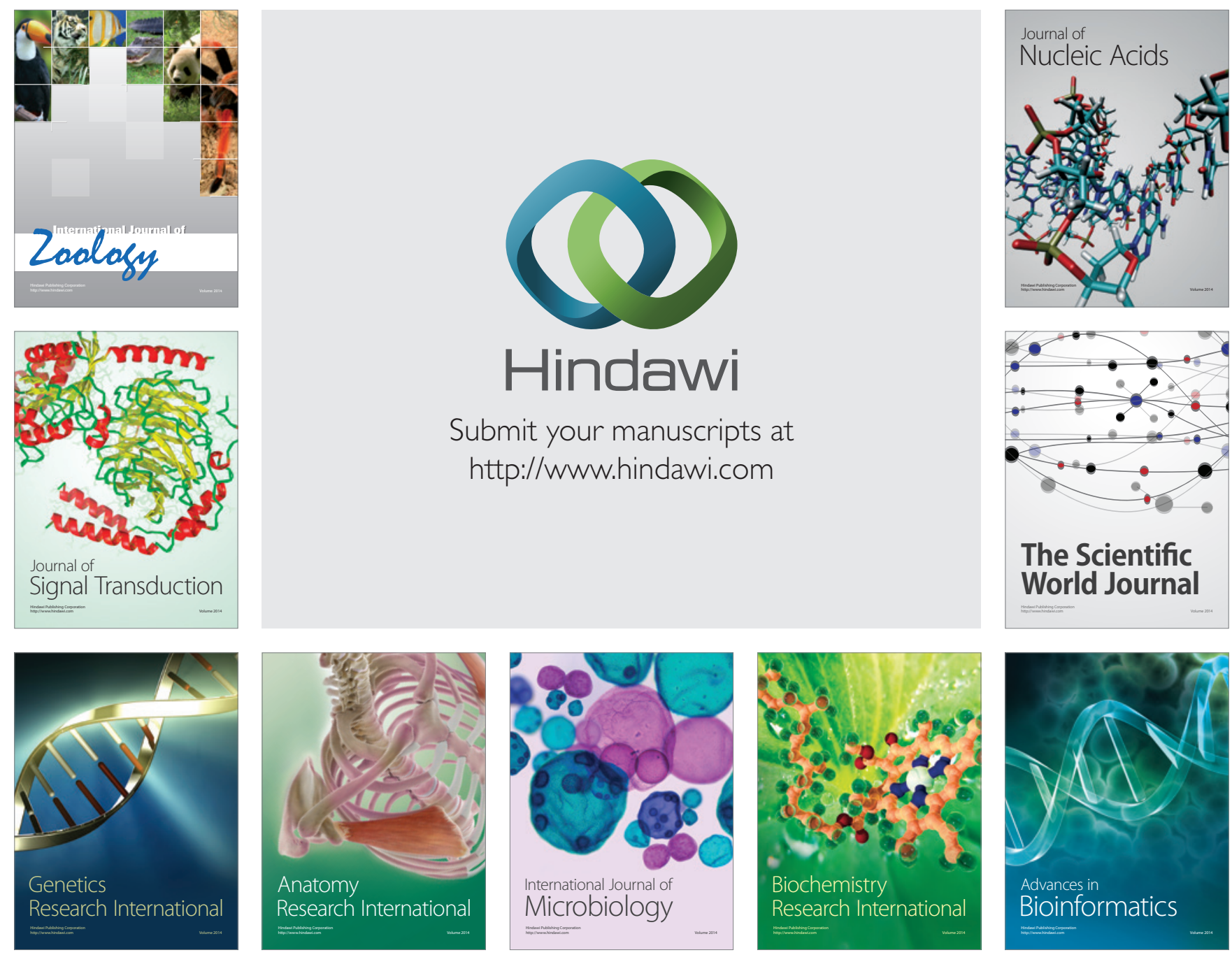

The Scientific World Journal
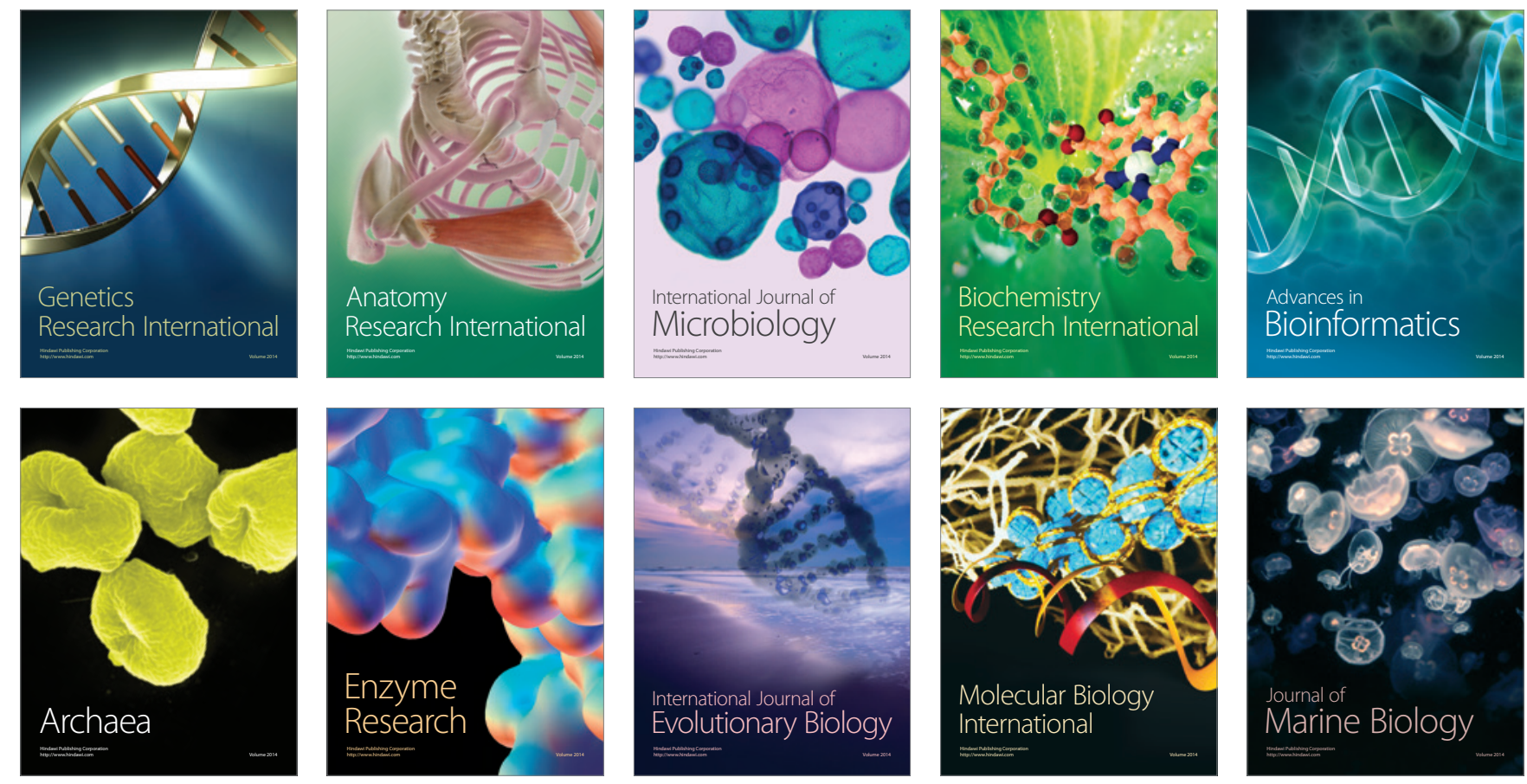